\title{
Effects of retro-nasal aroma release on satiation
}

\author{
Rianne M. A. J. Ruijschop ${ }^{1}$, Alexandra E. M. Boelrijk ${ }^{1}$, Jacob A. de $\mathrm{Ru}^{2}$, Cees de $\mathrm{Graaf}^{3}$ \\ and Margriet S. Westerterp-Plantenga ${ }^{4}$ \\ ${ }^{1}$ NIZO Food Research, Kernhemseweg 2, PO Box 20, 6710 BA Ede, The Netherlands \\ ${ }^{2}$ Department of Otorhinolaryngology, University Medical Centre Utrecht, PO Box 85500, 3508 GA Utrecht, The Netherlands \\ ${ }^{3}$ Division of Human Nutrition, Department of Agrotechnology and Food Sciences, Wageningen University, PO Box 8129,6700 EV \\ Wageningen, The Netherlands \\ ${ }^{4}$ Department of Human Biology, Maastricht University, PO Box 616, 6200 MD Maastricht, The Netherlands
}

(Received 5 April 2007 - Revised 6 August 2007 - Accepted 24 August 2007 - First published online 22 October 2007)

It is suggested that the brain response of a food odour sensed retro-nasally is related to satiation. The extent of retro-nasal aroma release during consumption depends on the physical structure of a food, i.e. solid foods generate a longer, more pronounced retro-nasal aroma release than liquid foods. The aim of this study was to investigate if a beverage becomes more satiating when the retro-nasal aroma release profile coincides with the profile of a (soft) solid food. In a double-blind placebo-controlled randomised cross-over full factorial design, twenty-seven healthy subjects (fourteen males and thirteen females; aged $16-65$ years; BMI $19-37 \mathrm{~kg} / \mathrm{m}^{2}$ ) were administered aroma profiles by a computer-controlled stimulator based on air dilution olfactometry. Profile A consisted of a profile that is obtained during consumption of normal beverages. Profile B is normally observed during consumption of (soft) solids. The two profiles were produced with strawberry aroma and administered in a retro-nasal fashion, while the subjects consumed a sweetened milk drink. Before, during and after the sensory stimulation, appetite profile measurements were performed. Subjects felt significantly more satiated if they were aroma stimulated with profile B $(P=0.04)$. After stimulation with sweet strawberry aroma, there was a significant decrease in desire to eat sweet products $(P=0.0001)$. In conclusion, perceived satiation was increased by altering the extent of retro-nasal aroma release.

\section{Satiation: Retro-nasal aroma stimulation: Flavour: Olfactometry}

In man, satiation is to a large extent obtained by sensory effects, generated through the smell, taste, colour, temperature and texture of food. It is likely that these factors contribute to the inhibition of eating while finishing a course or a meal ${ }^{(1)}$. There are quantitative reports that not all food types result in the same intensity or duration of sensory stimulation ${ }^{(2,3)}$. The extent of sensory stimulation may be related to meal termination. Liquid foods appear to be less satiating than (soft) solid foods ${ }^{(4-7)}$. Differences in structure and composition of the food may be (partly) responsible for this effect.

In view of the obesity problem one of the targets is to develop foods that combine liking with limited food intake, by enhancing satiation signals. In this respect, the role of aroma as a sensory trigger in satiety mechanisms is of interest ${ }^{(8,9)}$.

During the consumption of a meal, aroma molecules either reach the olfactory epithelium orthonasally (perceived as originating from the external world) or retro-nasally (perceived as arising from the mouth $)^{(10,11)}$. The brain response, i.e. neural brain activation to a retro-nasally sensed food odour is signalling the perception of food ${ }^{(12)}$. The latter is hypothesised to be related to satiation. From previous work, it is known that the physical structure of a food that is consumed is important for the extent of retro-nasal aroma release during consumption ${ }^{(13-16)}$. Additionally, interpersonal differences are important for retro-nasal aroma release efficiency. These are factors that are likely uncontrolled by a person, e.g. saliva production, nasal anatomy and oral processing habits ${ }^{(17-21)}$. The present study focuses on differences in food characteristics related to the extent of retro-nasal aroma release that they evoke. It appeared that there was a relatively much longer retro-nasal aroma release profile when consuming cheese instead of a beverage (Fig. 1). (Soft) solid foods like cheese have a more complex texture and therefore require more extensive chewing and swallowing, resulting in a relative long and high retro-nasal aroma release profile. On the other hand, consumption of liquid food results in a relatively short and more spiked, limited retro-nasal aroma release pattern ${ }^{(22-24)}$. These differences may be one of the reasons why people become more satiated by a (soft) solid food compared to a beverage ${ }^{(4-7)}$.

In order to study this hypothesis, the effect of the extent of retro-nasal aroma stimulation on food intake and satiation was investigated. Using a computer-controlled stimulator based on air dilution olfactometry, aroma stimuli can be administered separately from other stimuli, such as different ingredients,

Abbreviations: APCI-MS, atmospheric pressure chemical ionisation-MS; VAS, visual analogue scale.

* Corresponding author: Rianne M. A. J. Ruijschop, fax +31 318650400, email Rianne.Ruijschop@nizo.nl 
(a) PP29 savoury
$050726 R R 3$

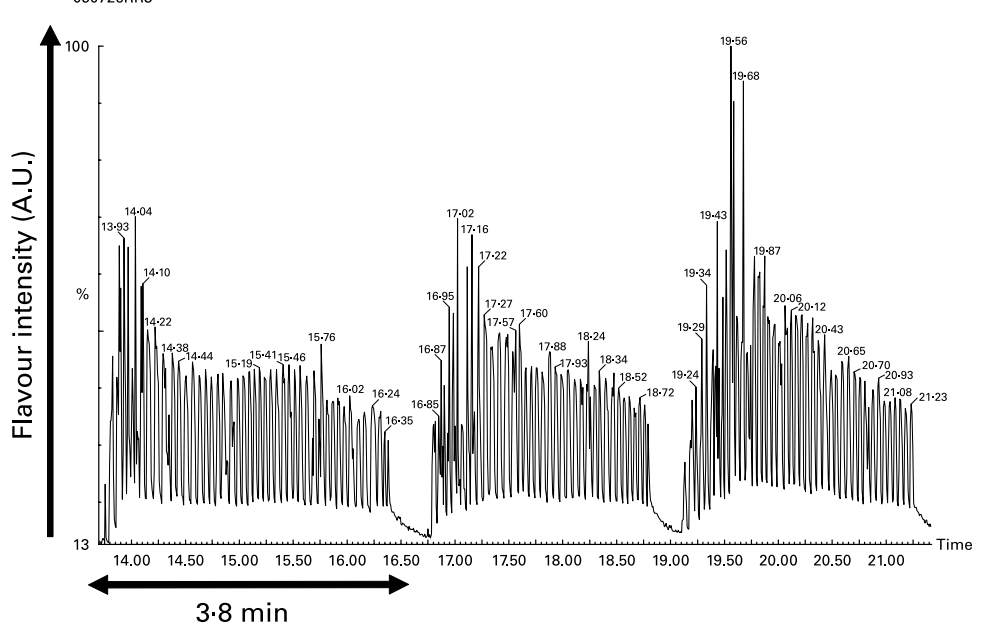

(b)

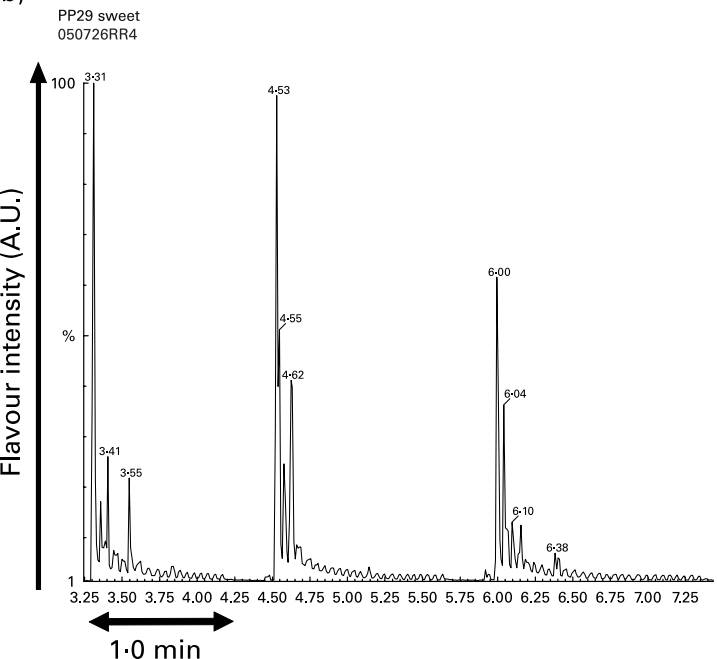

Fig. 1. Example of one subject, taken from Ruijschop et al. ${ }^{(22)}$, illustrating the differences in the extent of retro-nasal aroma stimulation between (a) the consumption of three times one mouthful (on average $8 \mathrm{~g}$ per mouthful) of cheese ((soft) solid food) and (b) three times one sip (on average $17 \mathrm{ml}$ per sip) of beverage (liquid food), measured by in vivo atmospheric pressure chemical ionisation-MS technology ${ }^{(23,24)}$. Since this illustration is comparison-wise, expression of the flavour intensity in arbitrary units (A.U.) is sufficient to analyse differences ${ }^{(25)}$. As appears from the triplicate measurement, people are reproducible in the morphology and intensity of their aroma release profile.

textures and tastes (Fig. 2). Hence, the relative importance of aroma stimuli apart from other stimuli on the short-term appetite profile and subsequent energy intake in normal-weight and overweight men and women was investigated. The aim of the present study was to determine whether a beverage becomes more satiating when the retro-nasal aroma release profile coincides with the profile of a (soft) solid food.

\section{Subjects and methods}

Subjects

Twenty-seven healthy subjects (fourteen men and thirteen women) aged 18-65 years living in Ede and surroundings were recruited through the local newspapers. The subjects included normal-weight, overweight and obese subjects, with a BMI of $19-37 \mathrm{~kg} / \mathrm{m}^{2}$. BMI was calculated as body weight (kg) divided by height (m) squared. Body weight was measured without wearing shoes using a calibrated scale which was accurate to $0.1 \mathrm{~kg}$ (Inventum, Veenendaal, The Netherlands). At the same time without wearing shoes, height was measured with a wall-mounted stadiometer (Microtoise mabo 4116, Brevete, France).

Subjects' degrees of dietary restraint were determined using the Dutch translation of the Three-Factor Eating Questionnaire ${ }^{(26)}$. Based on the outcome of the Three-Factor Eating Questionnaire subjects were selected with low scores on dietary restraint (i.e. scores $\leq 9$ ), disinhibition (i.e. emotional eating) (i.e. scores $\leq 8$ ) and physiological hunger (i.e. scores $\leq 8$ ). In addition, based on self-report, subjects were not allergic to, nor did they have an aversion to, any of the food ingredients used in the present study. Subject characteristics, including Three-Factor Eating Questionnaire scores, are summarised in Table 1. Subjects were fully informed about the course of the test day and gave their written, informed consent. To prevent response-bias the participants were given no information about the hypothesis and nature of the predictions of the experiment.
They were only aware of the fact that the study was about sensory stimulation and satiety. The study was approved by the Medical Ethical Committee of Wageningen University.

\section{Preparation of products}

Sweetened milk drink. For the preparation of the sweetened milk drink, $10 \%$ sucrose (Suiker Unie, Oud Gastel, The Netherlands) and six droplets (i.e. $0.36 \mathrm{ml}$ in total) of pink food colour (Städter $\mathrm{GmbH}$, Grünberg, Germany) were added to 1 litre of semi-skimmed (1.5\% fat) pasteurised milk (private label, Albert Heijn Zaandam, The Netherlands). The metabolisable energy of 1 litre of sweetened milk drink was $3.7 \mathrm{MJ} ; 15.4 \%$ of energy as fat, $68.6 \%$ as carbohydrate and $15.4 \%$ as protein.

Sweetened strawberry-flavoured milk drink. In order to prepare the sweetened strawberry-flavoured milk drink, $10 \%$ sucrose (Suiker Unie), $60 \mathrm{mg}$ strawberry aroma ${ }^{(27)}$ and six droplets (i.e. $0.36 \mathrm{ml}$ in total) of pink food colour (Städter $\mathrm{GmbH})$ were added to 1 litre of semi-skimmed ( $1.5 \%$ fat) pasteurised milk (private label, Albert Heijn Zaandam). The metabolisable energy and macronutrient composition of the sweetened strawberry-flavoured milk drink were similar to the sweetened milk drink ( 1 litre, $3.7 \mathrm{MJ} ; 15.4 \%$ of energy as fat, $68.6 \%$ as carbohydrate and $15.4 \%$ as protein).

Strawberry aroma. The strawberry aroma used was the standard flavour of the COST 921 action $^{(27)}$, designed and supplied by Givaudan (Geneva, Switzerland), which contains fifteen components including ethyl butyrate $(90 \mathrm{mg} / \mathrm{g})$, methyl dihydrojasmonate $(5 \mathrm{mg} / \mathrm{g})$, methyl cinnamate $(24 \mathrm{mg} / \mathrm{g})$, vanillin $(5 \mathrm{mg} / \mathrm{g})$, ethyl hexanoate $(50 \mathrm{mg} / \mathrm{g})$, benzyl acetate $(2 \mathrm{mg} / \mathrm{g}), \gamma$-decalactone $(20 \mathrm{mg} / \mathrm{g})$, hexanal $(1 \mathrm{mg} / \mathrm{g})$, cis-3-hexenol $(15 \mathrm{mg} / \mathrm{g}), \quad \beta$-ionone $(1 \mathrm{mg} / \mathrm{g})$, ethyl iso-pentanoate $(10 \mathrm{mg} / \mathrm{g})$, methyl anthranilate $(1 \mathrm{mg} / \mathrm{g})$, furaneol $(5 \mathrm{mg} / \mathrm{g})$, styrallyl acetate $(1 \mathrm{mg} / \mathrm{g})$, cis-3-hexenyl acetate $(5 \mathrm{mg} / \mathrm{g})$, and triacetin $(795 \mathrm{mg} / \mathrm{g})$ as a solvent. Prior to use in the olfactometer, 


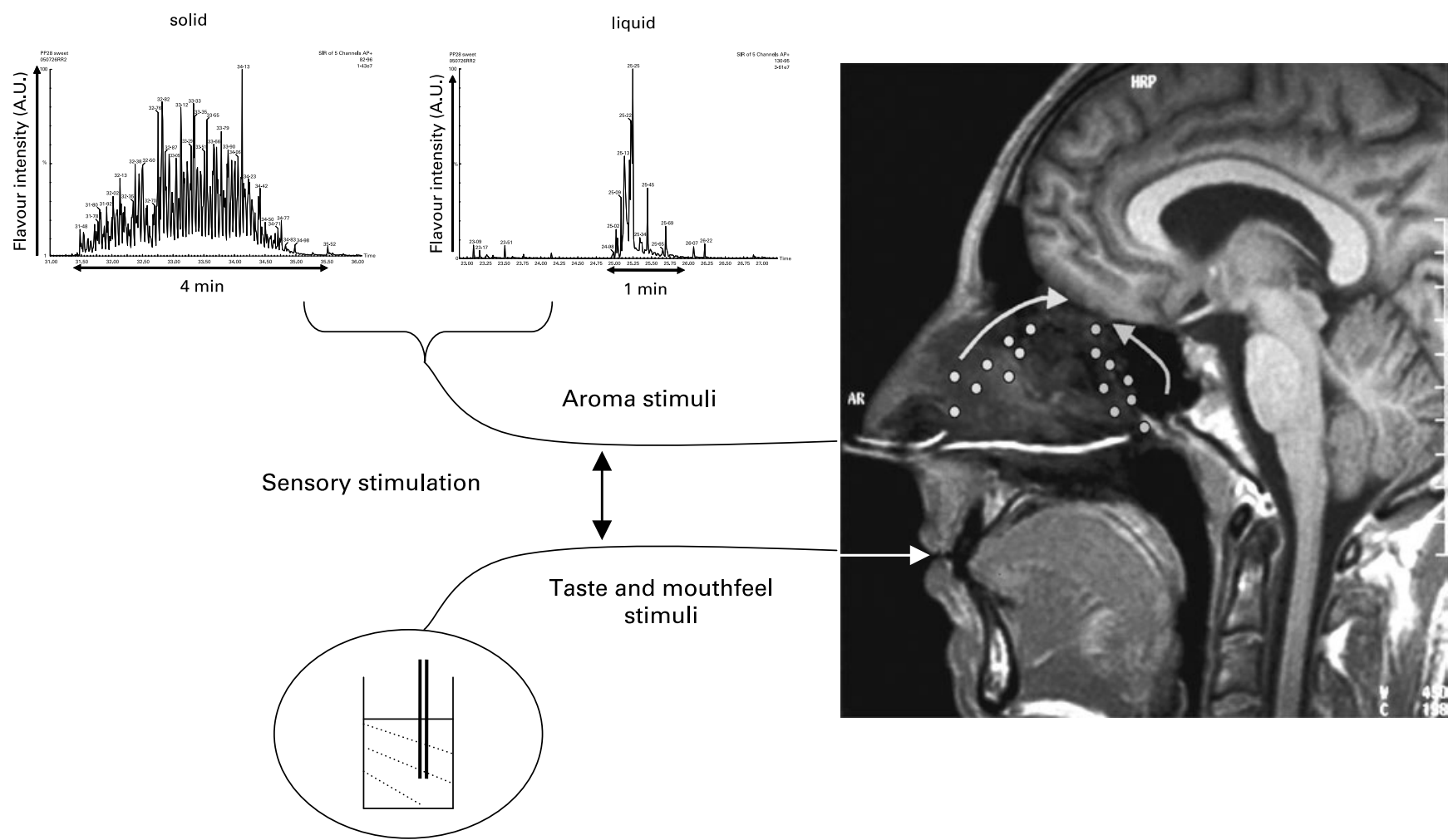

'Beverage with straw'

Fig. 2. Schematic representation of the approach used in the present study. Using a computer-controlled stimulator based on air dilution olfactometry, aroma stimuli can be administered in a retro-nasal fashion separately from other stimuli, such as taste and mouthfeel. An MRI image showing placement of the nasal cannulae at the external nares to achieve orthonasal delivery, and at the retropharynx, to achieve retro-nasal delivery. Dots and arrows depict the idealised distribution and flow direction of odorants delivered orthonasally (via the external nares) or retro-nasally (via the retropharynx). Reprinted from Small et al. ${ }^{\text {(12) }}$, with permission from Elsevier. All aroma release profiles which were retro-nasally delivered in the nose were combined with the taste and mouthfeel sensation of a sweetened milk drink in the mouth. A.U., arbitrary units.

the strawberry flavour was diluted 1000-fold in propylene glycol (Sigma-Aldrich Chemie GmbH, Germany).

Chocolate milk drink. Commercially available semiskimmed ( $1.5 \%$ fat) UHT chocolate milk drink was used (Bonomel, Albert Heijn Zaandam, The Netherlands). The metabolisable energy of 1 litre of chocolate milk drink was $3.0 \mathrm{MJ} ; 17.7 \%$ of energy as fat, $63.7 \%$ as carbohydrate and $18.6 \%$ as protein.

\section{Aroma stimulation}

The strawberry aroma was administered by means of a tailored computer-controlled four-channel olfactometer based on air-dilution olfactometry (OM4; Burghart, Wedel, Germany). As already described by Visschers et al. ${ }^{(28)}$, delivering foodrelated aroma stimuli via an olfactometer to subjects involves a variety of parameters and matching the aroma stimuli to such a level that can be genuinely related to food is a complex process. The approach that was used is based on the knowledge of measuring aroma release in vivo in real time using atmospheric pressure chemical ionisation-MS (APCI-MS) ${ }^{(24,29-31)}$. In practice, the Teflon tubing outlet of the olfactometer is directly attached to the APCI-MS inlet capillary. In this way, the timing and intensity of the aroma pulses generated by the olfactometer are matched with in vivo flavour release profiles of food products that initially were measured with the APCI-MS sampling the nose of a human subject. It was demonstrated that indeed the aroma profile that was generated with the olfactometer closely resembles the concentration of volatiles in the nose space measured for an individual subject eating or drinking a specific product. This enables the design of complete aroma release profiles that mimic those obtained by in vivo experiments during the consumption of foods ${ }^{(28)}$.

Table 1. Characteristics of the twenty-seven subjects who participated in the study*

(Mean values and standard deviations)

\begin{tabular}{|c|c|c|c|c|}
\hline & \multicolumn{2}{|c|}{$\begin{array}{c}\text { Normal-weight } \\
\quad(n 19)\end{array}$} & \multicolumn{2}{|c|}{$\begin{array}{l}\text { Overweight } \\
\quad(n 8)\end{array}$} \\
\hline & Mean & SD & Mean & SD \\
\hline Age (years) & 44 & 15 & 44 & 8 \\
\hline $\mathrm{BMI}\left(\mathrm{kg} / \mathrm{m}^{2}\right)$ & 22 & 3 & 29 & 3 \\
\hline \multicolumn{5}{|l|}{ TFEQ } \\
\hline Factor 1 (cognitive restraint) & 5 & 2 & 5 & 3 \\
\hline Factor 2 (disinhibition) & 4 & 2 & 5 & 2 \\
\hline Factor 3 (hunger) & 3 & 2 & 4 & 3 \\
\hline
\end{tabular}

TFEQ, Three-Factor Eating Questionnaire.

*The values of factors 1,2 and 3 are in the ranges $0-18,0-13$ and $0-14$, respectively. A higher value indicates more restraint, disinhibition or physiological hunger. All values are below medians that are usual. 
In the current set-up, the air flow out of the olfactometer was kept constant at 8 litres/min so as to be as close as possible to natural aroma release conditions during consumption. A complete aroma time-intensity release profile was administered by the olfactometer consisting of multiple aroma pulses. The aroma release curve that resembles the consumption of a liquid food (i.e. aroma profile A - Fig. 3) was delivered as a profile of three consecutive pulses, each lasting $3 \mathrm{~s}$, with interpulse intervals of $1 \mathrm{~s}$. The odorised-dilution air flow ratios, i.e. the amount of odour-enriched air $v$. the amount of odourless air for the three pulses within the profile were 4:4, 2:6, 1:7, with a total odour+dilution air flow of 8 litres $/ \mathrm{min}$. The aroma concentration in the delivered air corresponds linearly to the fraction of the total flow for flow rates up to 4 litres/min in each aroma vessel. The second aroma profile (i.e. aroma profile B - Fig. 3), mimicking the consumption of a (soft) solid food like Dutch Gouda cheese, varied only in the number of delivered consecutive pulses. In this profile ten pulses were delivered. The two aroma profiles thus primarily differed in length of the aroma release curve and not in concentration (height). Both profiles were designed in such a way that the envelope of the aroma pulses mimics the reflux of air that occurs during and after swallowing. Each subject received both aroma profiles with the same concentration of the strawberry aroma in a fully randomised order. For retro-nasal odour delivery, approximately $9 \mathrm{~cm}$ in length of a silicon tube (suction catheter CH 10; D-Care B.V., Houten, The Netherlands) was placed into the lower meatus of the right nasal cavity. Anterior rhinoscopy was performed to exclude major pathology. Introduction of the tubing to the nose was tolerated well by all subjects without causing congestion, epistaxis or mucus discharge. Subjects waited for $15 \mathrm{~min}$, in which they could relax and familiarise with the tubing. To what extent a subject felt comfortable was also recorded. The silicon tube was connected to the olfactometer while the subject was sitting straight up in a chair, enabling concurrent consumption of a beverage.

Subjects were connected to the olfactometer for $10 \mathrm{~min}$. The duration of aroma stimulation depended on the type of aroma stimulation they received. Both aroma stimulations consisted

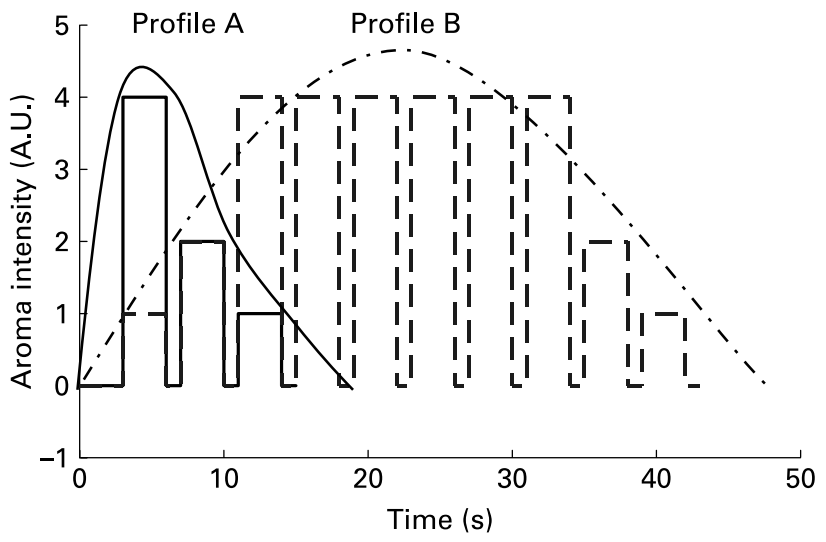

Fig. 3. Aroma release profiles delivered by olfactometer in the reference (i.e. liquid, profile $A,-$ ) and manipulated (i.e. (soft) solid, profile $B,--$ ) aroma stimulation. Since the present study is comparison-wise, expression of the flavour intensity in arbitrary units (A.U.) is sufficient to analyse differences ${ }^{(25)}$ The smoothed lines indicate the perceived aroma intensity, which is a continuous envelope. of ten aroma release profiles, starting every minute. All ten aroma release profiles which were retro-nasally delivered in the nose were combined with the taste and mouthfeel sensation of a sweetened milk drink $(10 \mathrm{ml})$ in the mouth. During one complete aroma stimulation experiment, every subject received ten such milk samples $(100 \mathrm{ml}$ in total), which were served at $7 \pm 1{ }^{\circ} \mathrm{C}$.

A specific protocol was established for the timing of aroma delivery. As $10 \mathrm{ml}$ is a normal quantity to be consumed in one sip, subjects were instructed to consume the entire sweetened milk sample in one sip using a straw. The aroma was delivered $3 \mathrm{~s}$ after the instruction to consume the sweetened milk sample. No specific instruction with regard to breathing was given. With the exception of strong breath intake through the nose, the total air flow of 8 litres/min from the olfactometer ensures delivery of the aroma to the olfactory epithelium. During the experiments, the subjects were closely observed in order to verify compliance with the protocol.

To prevent adaptation to the delivered aroma, the delay between the measurements amounted to a minimum of $17 \mathrm{~s}$ (i.e. the time interval between two successive aroma release profiles). Within this time interval, a continuous constant flow of clean air was maintained. After aroma stimulation, the silicon tube was removed and subjects went to another room for the remaining part of the experiment.

\section{Experimental design}

Separately, in order to prevent response-bias, additional sensory data were obtained to investigate whether the difference in the two aroma release profiles was large enough to be perceived as being different. Therefore, after the satiation experiments, a triangle test was performed with the subjects who participated in the study. Based on these results, it could be checked whether the intervention was successful.

For the satiation experiments, each subject visited the test location twice in the morning. Between each visit there was a time interval of 1 week. Before starting the experiment, daily dietary energy requirements were calculated individually by multiplying the BMR by an activity index of 1.75 . The BMR was calculated according to the equation of Harris \& Benedict $^{(32)}$. Subjects were asked to consume $10 \%$ of the daily dietary energy requirements for breakfast at home, which varied per person from 836.8 to $1464.4 \mathrm{~kJ}$ (from 200 to $350 \mathrm{kcal}$ ). In addition, the subjects were requested to consume the same type and amount of breakfast when visiting the laboratory the second time. Based on this individually standardised breakfast, subjects visited the laboratory every time with comparable feelings of hunger and satiety. This was confirmed by a baseline measurement before the start of the aroma stimulation.

In a double-blind placebo-controlled randomised crossover full factorial design subjects were administered two different aroma profiles using an olfactometer set-up as described earlier. Before, during and after the sensory stimulation, appetite profile measurements were performed. After sensory stimulation actual beverage intake of the sweetened strawberry-flavoured milk drink was measured. In addition, liking of the sweetened strawberry-flavoured milk drink $v$. the chocolate milk drink was measured. The design of a test day is represented schematically in Fig. 4. 


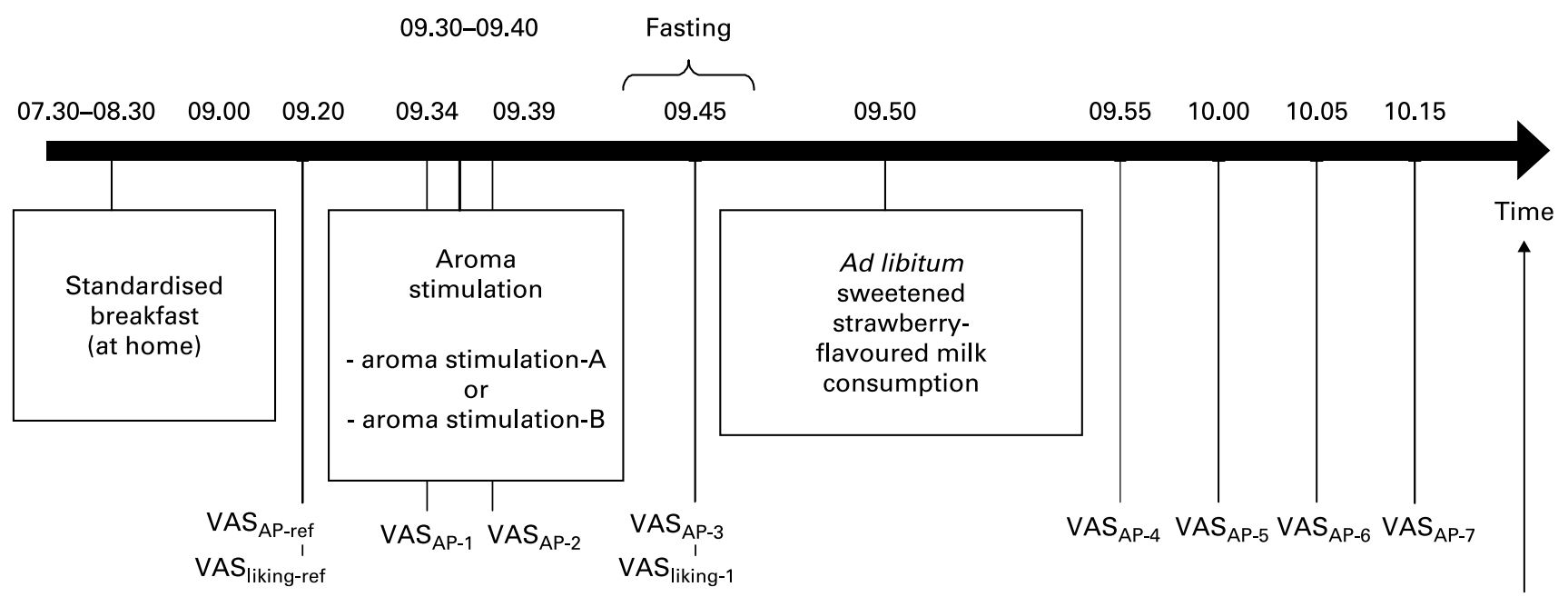

Fig. 4. Overview of the test day protocol. Subjects came twice to the laboratory, a week apart, and received either the reference (i.e. liquid) aroma stimulation-A or the manipulated (i.e. (soft) solid) aroma stimulation-B in a fully randomised order. Appetite profiles were recorded on a $100 \mathrm{~mm}$ visual analogue scale (VAS) at regular time-points $\left(\mathrm{VAS}_{\mathrm{AP} \text {-ref }}\right.$ to $\left.\mathrm{VAS}_{\mathrm{AP}-7}\right)$. To determine possible sensory-specific satiety effects, hedonic ratings were recorded for the sweetened strawberry-flavoured milk drink and the chocolate milk drink on a $100 \mathrm{~mm}$ VAS (VAS liking-ref and VAS liking-1 $_{\text {- }}$. In addition, 5 min after the subjects had been aroma stimulated, the amount of sweetened strawberry-flavoured milk consumed ad libitum was measured.

\section{Sensory evaluation of the aroma profiles}

A triangle test was performed in order to investigate whether the difference in the two aroma profiles was large enough to be perceived as being different. Using the olfactometer (OM4; Burghart), twenty-five subjects received four triangles each in a retro-nasal fashion. These triangles consisted of three stimuli, i.e. either two liquid (profile A) and one (soft) solid (profile B) aroma release profile or two (soft) solid (profile B) and one liquid (profile A) aroma release profile in a fully randomised order. Subjects were asked to pick out the odd stimulus.

Data analysis of triangle test. The number of correct responses (i.e. correctly identified odd stimuli) and total responses of the triangle test were counted. Data were treated as though there were 100 individual judges, instead of four replicates from twenty-five judges. To check if this was statistically valid, the possibility of non-independent judgements among replications was tested. The proportions of correct decisions between the replicates were not significantly different. Therefore, the data could be combined and the combined data may be analysed without reference to the individual replications ${ }^{(33)}$.

It was determined if the number correct for the number tested (i.e. 100) was equal to or larger than the number indicated in the suitable statistical table (i.e. forty-two), i.e. the minimum number of correct responses required for significant difference at a significance level of $\alpha=0.05^{(34)}$.

\section{Measurements}

Short-term appetite profile. The appetite profile, i.e. ratings of hunger, fullness, satiety, desire to eat, and thirst were recorded on a $100 \mathrm{~mm}$ visual analogue scale (VAS) (anchored for each with 'not at all' and 'very much') at regular timepoints before, during and after both the aroma stimulation and the ad libitum beverage intake (see $\mathrm{VAS}_{\mathrm{AP}}-$ Fig. 4). In addition, at the same time-points desire to eat sweet products and desire to eat savoury products were recorded on $100 \mathrm{~mm}$ VAS anchored with 'not at all' and 'very much'. In Dutch language the exact wording for recording of the appetite profile ratings was: 'Hoeveel honger heeft $\mathrm{u}$ ?; Hoe vol voelt u zich?; Hoe verzadigd voelt u zich?; Hoe groot is uw wens om te eten?; Hoeveel dorst heeft u?; Hoeveel trek heeft $\mathrm{u}$ in iets zoets?; Hoeveel trek heeft $\mathrm{u}$ in iets hartigs? ${ }^{(26)}$. All rating scales were provided on separate sheets that were collected after each rating.

Actual beverage intake. To measure the effect of the type of aroma stimulation on actual food consumption, 5 min after the subjects had been aroma stimulated, they were offered 1 litre of sweetened strawberry-flavoured milk drink, served with a straw in a jar covered with aluminium foil at $7 \pm 1{ }^{\circ} \mathrm{C}$, from which they could drink ad libitum. The amount offered was such that there were always leftovers. After consumption the amount of beverage consumed was measured for each subject (Mettler-Toledo balance; Greifensee, Switzerland).

Pleasantness of flavour rating. To determine possible sensory-specific satiety effects, defined as the decrease in pleasantness of a food after it is eaten compared with the decrease in pleasantness of foods that were tasted but not eaten to satiation ${ }^{(35)}$, two different kinds of dairy products were used: a sweetened strawberry-flavoured milk drink and chocolate milk drink. The sweetened strawberry-flavoured milk drink was the same drink as used for the actual beverage intake measurements. Before and after the aroma stimulation, subjects received $10 \mathrm{ml}$ of both sweetened strawberry-flavoured milk drink and chocolate milk drink. Samples were served at $7 \pm 1{ }^{\circ} \mathrm{C}$. After drinking the sweetened strawberryflavoured milk drink sample, subjects were asked to scale their hedonic rating (100 mm VAS anchored with 'not pleasant at all' and 'very pleasant') and their desire to drink this sweetened strawberry-flavoured milk drink (100 mm VAS anchored with 'not at all' and 'very much') (see $\mathrm{VAS}_{\text {liking }}-$ Fig. 4). Subsequently, the same measures for the chocolate milk drink were recorded. 
Data analysis of short-term appetite profile, actual beverage intake and pleasantness of flavour. VAS ratings were measured in millimetres from the left ('not at all') end of the scale. Since there were no significant differences in VAS rating at baseline measurement, $\Delta$ VAS ratings, i.e. changes in VAS ratings, were calculated by subtracting the ratings at the time-point before aroma stimulation took place $\left(\mathrm{VAS}_{\mathrm{AP}-\mathrm{ref}}\right.$ for appetite profile ratings and $\mathrm{VAS}_{\text {liking-ref }}$ for hedonic ratings) from the ratings at the different time-points after aroma stimulation $\left(\mathrm{VAS}_{\mathrm{AP}-1}\right.$ to $\mathrm{VAS}_{\mathrm{AP}-7}$ for appetite profile ratings and $\mathrm{VAS}_{\text {liking-1 }}$ for hedonic ratings). All data are presented as means with their standard errors of the mean. Actual beverage intake and the different VAS ratings were compared between the two aroma stimulations by using paired $t$-tests and also ANOVA with repeated measures. Post hoc, for each comparison separately, ANOVA with repeated measures was also used. For all data analyses the statistical packages SAS, release 9.1 (SAS Institute Inc., Cary, NC, USA) were used. $P<0.05$ was considered statistically significant.

\section{Results}

Sensory evaluation of the aroma profiles

From the 100 triangles that were carried out in the triangle test, seventy-three correct responses were counted. This implies that subjects were able to evaluate the two aroma release profiles as significantly different $(P<0.001)$; thus most of them were able to discriminate between the liquid (profile A) and (soft) solid (profile B) aroma release profile. Among the responses, it was not possible to identify sensitive and insensitive subjects. In the satiation experiments, the timing for each sip of sweetened milk drink while an aroma profile was delivered did not vary between the two aroma profiles A and B. The only difference in sensory experience that was perceived by the subjects was a lingering of aroma (i.e. aftertaste) after swallowing the sweetened milk sample when aroma profile B was administered. By interviewing subjects afterwards, it appeared that they were completely unaware that the strawberry-flavoured sweetened milk drink consisted of separately delivered aroma and taste/mouthfeel stimuli.

\section{Short-term appetite profile}

Before, during and after the sensory stimulation, appetite profile measurements were performed. Figs. 5 and 6 show, respectively, the results of the different types of aroma stimulation on the change in VAS ratings of satiation and the effect of aroma stimulation in general on the change in desire to eat sweet and savoury products VAS rating.

A significant difference was demonstrated in perceived satiation between an olfactometer delivery of a classical beverage aroma profile (profile A; $\Delta$ mean response at $\mathrm{VAS}_{2} 3 \cdot 0$ (SEM 5.3) $\mathrm{mm}$ ) compared to an olfactometer delivery of a (soft) solid aroma profile (profile $\mathrm{B} ; \Delta$ mean response at $\mathrm{VAS}_{2} 14.5$ (SEM 5.3) mm). From Fig. 5 it can be concluded that during aroma stimulation $\left(\mathrm{VAS}_{2}\right)$ subjects felt more satiated if they were aroma stimulated with profile $\mathrm{B}\left(F_{(1,390)} 4 \cdot 24\right.$; $P=0 \cdot 04)$. In addition, with regard to desire to eat sweet and savoury products ratings, there was a decrease in desire to

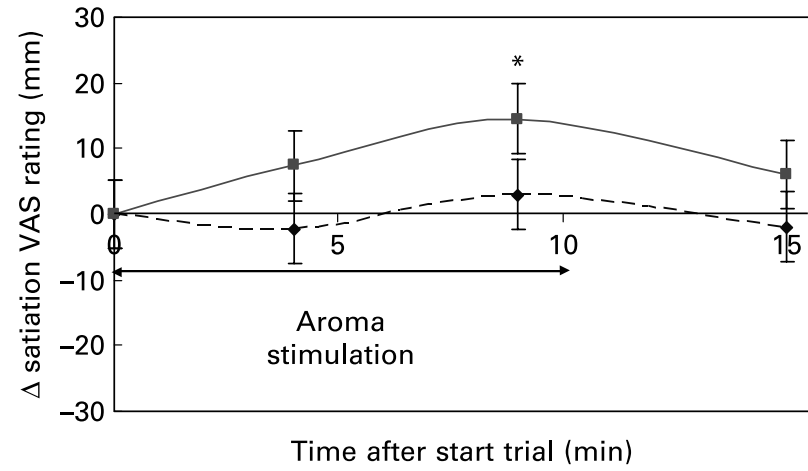

Fig. 5. Change $(\Delta)$ in satiation visual analogue scale (VAS) rating after stimulation with aroma profile $A(\diamond) v$. aroma profile $B(\square)$. Values are means with their standard errors depicted by vertical bars. ${ }^{*}$ Effect of type of aroma stimulation (profile $\mathrm{A}$ or $\mathrm{B})$ on $\triangle$ satiation VAS rating $(P<0.05)$.

eat sweet products after stimulation with the sweet strawberry aroma, irrespective of the type of aroma stimulation ( $\Delta$ mean - 14.6 (SEM 4.4) mm). Overall, after stimulation with the strawberry aroma, the desire to eat sweet products decreased significantly $\left(F_{(1,390)} 8 \cdot 17 ; P=0 \cdot 0001\right)$. As expected, no significant change in desire to eat savoury products after aroma stimulation with the sweet strawberry aroma was observed ( $\Delta$ mean 0.7 (SEM 4.9) mm; $F_{(1,390)} 0.54 ; P=0.80 ;$ Fig. 6).

Post hoc, after aroma stimulation a significant age effect was observed; i.e. older people (age $\geqq 45$ years) felt on average less satiated (peak values for $\Delta$ satiation VAS rating $=3$ and $13 \mathrm{~mm}$ for older and younger people, respectively) and had less decrease in desire to eat sweet products $(\Delta$ desire to eat sweet products VAS rating $=-8$ and $-18 \mathrm{~mm}$ for older and younger people, respectively; $P<0.05$; data not shown).

\section{Actual beverage intake}

After sensory stimulation actual beverage intake of sweetened strawberry-flavoured milk drink was measured. The amount of sweetened strawberry-flavoured milk drink consumed

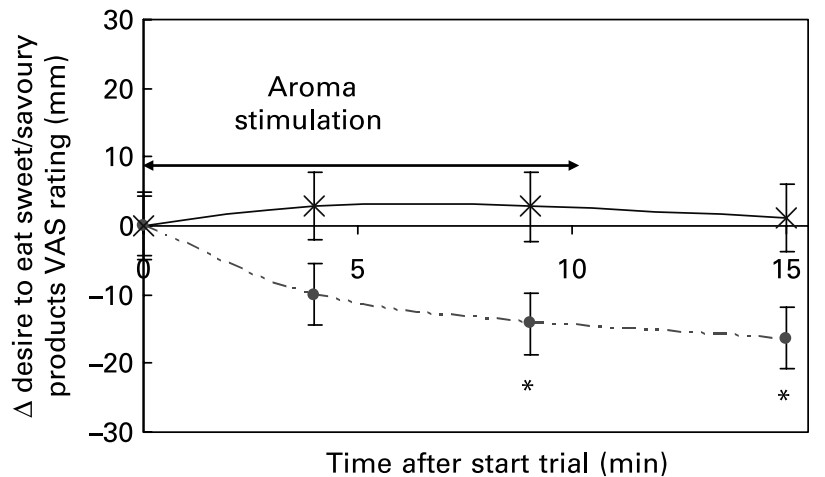

Fig. 6. Change $(\Delta)$ in desire to eat sweet $(\bullet)$ or savoury $(X)$ products visual analogue scale (VAS) rating after stimulation with sweet strawberry aroma. Since there were no significant differences in VAS ratings after stimulation with aroma profile $A v$. aroma profile $B$, data from aroma profile $A$ and $B$ were averaged. Values are means with their standard errors depicted by vertical bars. ${ }^{*}$ Effect of aroma stimulation on $\Delta$ desire to eat sweet products VAS rating $(P<0.05)$. 
ad libitum did not differ significantly between the two aroma stimulations (respectively, 187 (SEM 16) $\mathrm{ml}$ (range $3.7-526.2 \mathrm{ml}$ ) after aroma stimulation with profile $\mathrm{A}$ and 185 (SEM 16) $\mathrm{ml}$ (range 10.8-600.8 ml) after aroma stimulation with profile B) $\left(F_{(1,25)} 0 \cdot 01 ; P=0.94\right.$; Fig. 7). Since there was no gender effect in the actual beverage intake data $\left(F_{(1,25)} 0 \cdot 18, P=0 \cdot 68\right)$, males and females were analysed together. After calculating to what extent energy consumed $a d$ libitum contributed to the daily dietary energy requirements, it appeared that overweight subjects (BMI $>25 \mathrm{~kg} / \mathrm{m}^{2}$ ) consumed more compared to the normal-weight subjects $\left(B M I \leq 25 \mathrm{~kg} / \mathrm{m}^{2}\right)$. Actual beverage intake, expressed as a percentage of the daily dietary energy requirements, was positively related to BMI after aroma stimulation with both profile $\mathrm{A}$ and profile $\mathrm{B}$ (for aroma stimulation with profile $\mathrm{A}: R^{2} 0 \cdot 17$; $P=0.03$; and for aroma stimulation with profile $\mathrm{B}: R^{2} 0.34$; $P=0 \cdot 001$, respectively).

\section{Pleasantness of flavour rating}

Even though after aroma stimulation the pleasantness of flavour decreased for both the sweetened strawberry-flavoured milk ( $\Delta$ mean -1.4 (SEM 2.2) $\mathrm{mm}$ ) and the chocolate milk drink ( $\Delta$ mean -3.4 (SEM 1.7$) \mathrm{mm}$ ), no significant effect upon the pleasantness of flavour was observed $\left(F_{(1,25)}<1.59 ; P>0 \cdot 21\right)$. Subjects perceived no decrease in pleasantness of flavour or desire to drink the sweetened strawberry-flavoured milk drink compared to the chocolate milk drink.

\section{Discussion}

Using a triangle test, differences with respect to duration of the olfactory stimulation were determined using the (untrained) consumer subjects. Subjects were able to distinguish the two different aroma profiles as significantly different when they were delivered to them in a consecutive order. However, it has to be noted that during the satiation measurements, which were 1 week apart, the subjects were not consciously aware of the differences in delivered aroma release profiles A and B. By interviewing subjects afterwards, it appeared that subjects may be aware to some extent of the delivery of aroma, but they did not perceive any difference in the type of aroma stimulation they received when visiting the laboratory the second time 1 week later compared to the

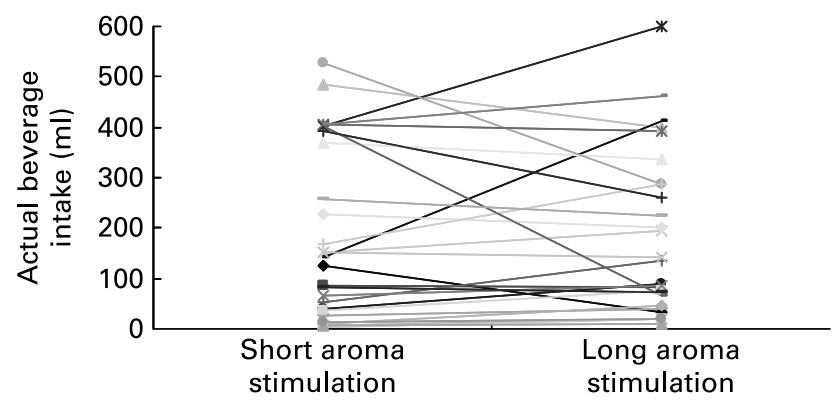

Fig. 7. The amount of sweetened strawberry-flavoured milk drink consumed ad libitum after the two aroma stimulations by the twenty-seven subjects. There was no significant difference in actual beverage consumption between the two aroma stimulations $\left(F_{(1,25)} 0.01 ; P=0.94\right)$. first time. This indicates that there was no response bias. In conclusion, a significant difference demonstrated in perceived satiation between olfactometer delivery A and B can be perceived, but during the satiation experiments, subjects were not consciously aware of the differences.

The demonstrated difference in perceived satiation between an olfactometer delivery of a classical beverage aroma profile A compared to an olfactometer delivery of a (soft) solid aroma profile $\mathrm{B}$ is a meaningful result. To our knowledge, this is the first time that such a result has been observed. A beverage with an aroma release profile similar to a (soft) solid food (profile B) is able to increase the subject's feeling of satiation significantly (Fig. 5). Since the transit time in the oral cavity is relatively short with consumption of beverages, consumption of beverages usually results in relatively short and spiked aroma release patterns ${ }^{(22,24)}$. This limited retro-nasal aroma release efficiency may result in less sensory stimulation. The difference in the extent of retro-nasal aroma release between (soft) solid and liquid foods is most likely one of the reasons why people perceive to be more satiated by a (soft) solid food compared to a beverage.

It appeared that after stimulation with the strawberry aroma a significant decrease in desire to eat sweet products is observed, irrespective of the type of aroma stimulation (Fig. 6). This is due to sensory-related satiation. Apparently, the difference in aroma profiles $\mathrm{A}$ and $\mathrm{B}$ did not result in a difference in decrease in desire to eat sweet products. This may be due to a difference too small between both aroma profiles. Based on the results regarding desire to eat sweet products, it is in line with expectations that no significant change in desire to eat savoury products after aroma stimulation with the sweet strawberry aroma was observed (Fig. 6).

The fact that no significant difference was observed in actual beverage intake after an olfactometer delivery of a classical beverage aroma profile (A) compared to an olfactometer delivery of a (soft) solid aroma profile (B) was not unexpected. Energy intake during a meal was not related to pre-prandial satiety, similar to previous observations ${ }^{(7,36-38)}$. In fact, energy intake during a meal is related to the various parameters after the meal, i.e. postprandial satiety and intermeal interval ${ }^{(39)}$.

Furthermore, no significant difference in pleasantness of flavour rating of a sweetened strawberry-flavoured milk drink $v$. a chocolate milk drink after olfactometer delivery A or B appeared. A possible explanation could be that aroma was not the only determinative factor responsible for the outcome of the pleasantness of flavour ratings. It might be that congruency between sweet taste and aroma perception for both the strawberry and the chocolate drink plays a role ${ }^{(40)}$. Since the chocolate milk drink had a sweet taste too, this may be the sensory driver for pleasantness of flavour ratings and therefore there is limited difference between chocolate and strawberry-flavoured milk. This would indicate a generalisation over sweet products, thus a larger band-width, after aroma stimulation with sweet foods in general.

In addition, the higher satiation response after the (soft) solid aroma profile (profile B) compared to the liquid aroma profile (profile A) might be contributing to a learned response (i.e. conditioned satiation, cf. Booth et al. $^{(41)}$ and Gibson \& Brunstrom $\left.^{(42)}\right)$. In real life people may gradually learn that (soft) solid foods have a higher satiating capacity/energy 
content than liquid foods. The higher satiating effect of the (soft) solid aroma profile may be explained in terms of a longer nasal monitoring of odour release which is usually associated with a higher subsequent ingestion of energy.

An alternative explanation for the observed difference in appetite rating is a higher sensory-specific satiety effect of the (soft) solid aroma profile compared to the liquid aroma profile. The lack of significant differences in the pleasantness of the exposed relative to the unexposed flavour and in ad libitum intake makes this explanation less probable. However, it may be difficult to distinguish between a sensory-related satiation effect and sensory-specific satiety.

To summarise, by using this novel approach, i.e. delivering aroma stimuli separately from taste and mouthfeel, the relative importance of aroma stimuli on the short-term appetite profile and subsequent energy intake can indeed be determined. The present study demonstrates that a beverage is perceived as more satiating than the original beverage when the retronasal aroma release profile during consumption coincides with the profile of a (soft) solid food. Perceived satiation can thus be increased by altering the extent of aroma release. Despite changes in subjective experience, there is no impact on ad libitum amount consumed. This dissociation is a common observation in the field and similar to previous studies $^{7,36-38)}$. However, in a follow-up study it would be a great challenge to obtain also a significant effect on actual food intake.

The results of the present study are interesting for the development of foods that contain triggers that are able to induce or increase the feeling of satiation, for instance foods with an increase of aftertaste by lingering aroma, or long chewable food structures that evoke lots of oral processing and an increase in transit time in the oral cavity, resulting in a higher retro-nasal aroma release efficiency. These applications may lead to a higher quality or quantity of sensory stimulation, which in turn may lead to enhanced feelings of satiation. For example, people who are participating in a weight loss programme may benefit with these foods.

\section{Acknowledgements}

We acknowledge Marc Jacobs, Annereinou Dijkstra, Denise Jonker and Iris van Swam for their skilful assistance with the experimental design and measurements. We also thank Meike te Giffel for critical reading of the manuscript. R. M. A. J. R. designed the experiment, collected the data, analysed the data, and wrote the manuscript. A. E. M. B. provided significant advice on the study design, data analysis and helped prepare the manuscript. J. A. d. R. provided medical assistance during the experiment and reviewed the manuscript. C. d. G. and M. S. W.-P. provided significant advice with the design of the experiment, data analysis and writing of the manuscript. None of the authors had a personal or financial conflict of interest. This work was done within DiOGenes. DiOGenes is the acronym of the project 'Diet, Obesity and Genes' supported by the European Community (contract no. FOODCT-2005-513946). The parties of the project are listed on the website of the project: http://www.diogenes-eu.org/. Special acknowledgement is made to the Dutch Dairy Organization for co-financing this project.

\section{References}

1. Sorensen LB, Moller P, Flint A, Martens M \& Raben A (2003) Effect on sensory perception of foods on appetite and food intake: a review of studies on humans. Int $J$ Obes Relat Metab Disord 27, 1152-1166.

2. Vickers Z \& Holton EA (1998) A comparison of taste test ratings, repeated consumption, and postconsumption ratings of different strengths of iced tea. J Sensory Stud 13, 199-212.

3. Zandstra EH \& de Graaf C (1998) Sensory perception and pleasantness of orange beverages from childhood to old age. Food Qual Pref 9, 5-12.

4. Haber GB, Heaton KW, Murphy D \& Burroughs LF (1977) Depletion and disruption of dietary fibre. Effects on satiety, plasma-glucose, and serum-insulin. Lancet ii, 679-682.

5. Mattes RD \& Rothacker D (2001) Beverage viscosity is inversely related to postprandial hunger in humans. Physiol Behav 74, 551-557.

6. Mattes R (2005) Soup and satiety. Physiol Behav 83, 739-747.

7. Tsuchiya A, Almiron-Roig E, Lluch A, Guyonnet D \& Drewnowski A (2006) Higher satiety ratings following yoghurt consumption relative to fruit drink or dairy fruit drink. $J$ Am Diet Assoc 106, 550-557.

8. Hirsch AR \& Gomez R (1995) Weight reduction through inhalation of odorants. J Neurol Orthop Med Surg 16, 28-31.

9. Mayer SN, Davidson RS \& Hensley CB (1999) The role of specific olfactory stimulation in appetite suppression and weight loss. $J$ Adv Med 12, 13.

10. Murphy C, Cain WS \& Bathoshuk LM (1977) Mutual action of taste and olfaction. Sens Processes 1, 204-211.

11. Rozin P (1982) Taste-smell confusions and the duality of the olfactory sense. Percept Psychophys 31, 397-401.

12. Small DM, Gerber JC, Mak YE \& Hummel T (2005) Differential neural responses evoked by orthonasal versus retro-nasal odorant perception in humans. Neuron 47, 593-605.

13. Linforth RST, Baek I \& Taylor AJ (1999) Simultaneous instrumental and sensory analysis of volatile release from gelatine and pectin/gelatine gels. Food Chem 65, 77-83.

14. Cook DJ, Linforth RST \& Taylor A (2003) Effects on hydrocolloid thickeners on the perception of savoury flavors. J Agric Food Chem 51, 3067-3072.

15. Lethuaut L, Weel KG, Boelrijk AE \& Brossard CD (2004) Flavour perception and aroma release from model dairy desserts. Agric Food Chem 52, 3478-3485.

16. van Ruth SM, de Witte L \& Uriarte AR (2004) Volatile flavour analysis and sensory evaluation of custard desserts varying in type and concentration of carboxymethyl cellulose. J Agric Food Chem 52, 8105-8110.

17. Brown WE, Dauchel C \& Wakeling I (1996) Influence of chewing efficiency on texture and flavour perceptions of food. J Texture Stud 27, 433-450.

18. Buettner A, Beer A, Hanning C \& Settles M (2001) Observation of the swallowing process by application of videofluoroscopy and real-time magnetic resonance imaging consequences for retro-nasal aroma stimulation. Chem Senses 26, 1211-1219.

19. Buettner A, Beer A, Hanning C, Settles M \& Schieberle P (2002) Physiological and analytical studies on flavour perception dynamics as induced by eating and swallowing process. Food Qual Pref 13, 497-504.

20. Wright KM, Sprunt J, Smith AC \& Hills BP (2003) Modelling flavour release from a chewed bolus in the mouth. Part 1. Mastication. Int J Food Sci Technol 38, 351-360.

21. Pionnier E, Chabanet C, Mioche L, Le Quere JL \& Salles C (2004) 1. In vivo aroma release during eating of a model cheese: relationships with oral parameters. J Agric Food Chem 52, 557-564. 
22. Ruijschop RMAJ, Jacobs MA, Burgering MJM \& Boelrijk AEM (2007) Retro-nasal aroma release efficiency depends on both interpersonal and product differences. (In Preparation).

23. Brauss MS, Balders B, Linforth RST, Avison S \& Taylor AJ (1999) Fat content, baking time, hydration and temperature affect flavour release from biscuits in model-mouth and real systems. Flavour Fragr J 14, 351-357.

24. Weel KGC, Boelrijk AEM, Burger JJ, Gruppen H, Voragen AGJ \& Smit G (2003) A protocol for measurement of in vivo aroma release from beverages. J Food Sci 68, 1123-1128.

25. Taylor AJ, Linforth RST, Harvey BA \& Blake A (2000) Atmospheric pressure chemical ionisation mass spectroscopy for in vivo analysis of volatile flavour release. Food Chem 71, 327-338.

26. Westerterp-Plantenga MS, Rolland V, Wilson SAJ \& Westerterp KR (1999) Satiety related to $24 \mathrm{~h}$ diet-induced thermogenesis during high protein/carbohydrate versus high fat diets, measured in a respiration chamber. Eur J Clin Nutr 53, 1-8.

27. COST 921 action, http://www.cost921.uni-wuppertal.de (accessed 8 August 2006).

28. Visschers RW, Jacobs MA, Frasnelli J, Hummel T, Burgering M \& Boelrijk AEM (2006) Cross-modality of texture and aroma perception is independent of orthonasal or retro-nasal stimulation. J Agric Food Chem 54, 5509-5515.

29. Weel KGC, Boelrijk AEM, Burger JJ, Verschueren M, Gruppen H, Voragen AG \& Smit G (2004) New device to simulate swallowing and in vivo aroma release in the throat from liquid and semi-liquid food systems. J Agric Food Chem 52, 6564-6571.

30. van Loon WA, Linssen JP, Boelrijk AE, Burgering MJ \& Voragen AG (2005) Real-time flavour release from French fries using atmospheric pressure chemical ionization-mass spectrometry. J Agric Food Chem 53, 6438-6442.

31. de Kok PMT, Boelrijk AEM, de Jong C, Burgering MJM \& Jacobs MA (2006) MS-nose flavour release profile mimic using an olfactometer. In Developments in Food Science; Flavour
Science, Recent Advances and Trends, 43, pp. 585-599 [W Bredie and MA Petersen, editors]. Amsterdam: Elsevier.

32. Harris JA \& Benedict FG (1919) A Biometric Study of Basal Metabolism in Man. Publication no. 279. Washington, DC: Carnegie Institute of Washington.

33. Lawless HT \& Heymann H (1998) Sensory Evaluation of Food: Principles and Practices, pp. 121-139. New York: Chapman \& Hall.

34. Meilgaard M, Civille GV \& Carr BT (1999) Sensory Evaluation Techniques, 3rd ed., pp. 61-68. Boca Raton, FL: CRC Press.

35. Snoek HM, Huntjens L, van Gemert LJ, de Graaf C \& Weenen $\mathrm{H}$ (2004) Sensory-specific satiety in obese and normal-weight women. Am J Clin Nutr 80, 823-831.

36. Mattes R (1990) Hunger ratings are not a valid proxy measure of reported food intake in humans. Appetite 15, 103-113.

37. de Graaf C, Blom WAM, Smeets PAM, Stafleu A \& Hendriks HFJ (2004) Biomarkers of satiation and satiety. Am J Clin Nutr 79, 946-961.

38. Harper A, James A, Flint A \& Astrup A (2007) Increased satiety after intake of a chocolate milk drink compared with a carbonated beverage, but no difference in subsequent ad libitum lunch intake. Br J Nutr 97, 579-583.

39. Schilstra AJ (1981) Meal-interval correlations: what can they tell us? Physiol Behav 27, 299-304.

40. de Graaf C, Schreurs A \& Blauw YH (1993) Short-term effects of different amounts of sweet and nonsweet carbohydrates on satiety and energy intake. Physiol Behav 54, 833-843.

41. Booth DA, Lee M \& McAleavey C (1976) Acquired sensory control of satiation in man. Br J Psychol 67, 137-147.

42. Gibson EL \& Brunstrom JM (2007) Learned influences on appetite, food choice and intake: evidence in human beings. In Progress in Brain Research: Appetite and Body Weight - xIntegrative Systems and the Development of Anti-obesity Drugs, pp. 271-300 [SJ Cooper and TC Kirkham, editors]. London: Elsevier. 